\title{
The function of miRNAs in hepatocarcinogenesis induced by hepatitis B virus $\mathrm{X}$ protein (Review)
}

\author{
ZIYAO WANG, ZHONGJUN WU and PING HUANG \\ National Key Clinical Department, Department of Hepatobiliary Surgery, The First Affiliated Hospital of \\ Chongqing Medical University, Chongqing Medical University, Chongqing 400000, P.R. China
}

Received November 16, 2016; Accepted May 4, 2017

DOI: $10.3892 /$ or.2017.5716

\begin{abstract}
MicroRNAs are short RNAs that play a crucial role in all biological processes through post-transcriptional regulation for protein-coding genes and inducing mRNA degradation. Hepatitis B virus infection has been considered as a major risk factor in hepatocellular carcinoma, further research indicates that hepatitis $B$ virus $X$ protein $(\mathrm{HBX})$ is one of the critical links of hepatocarcinogenesis. HBx takes part in hepatocarcinogenesis via regulating transcription, signal transduction, apoptosis, protein degradation and DNA repair. miRNA is the important target gene of $\mathrm{HBx}$, their interaction impacts many tumor processes, such as proliferation, apoptosis, invasion, metastasis, differentiation and adipogenesis. In the present study we reviewed the current state of knowledge of regulation pathway of $\mathrm{HBx}$ acting on miRNAs, and focused on the role of their interplay in hepatocarcinogenesis.
\end{abstract}

\section{Contents}

1. Introduction

2. The mechanism and result of HBx acting on miRNA

3. The effect of the particular HBx form on miRNA

4. The influence of HBx through regulating miRNA for hepatocarcinogenesis

5. The effect of miRNA on HBV replication and HBx expression

6. Conclusion

Correspondence to: Professor Ping Huang, National Key Clinical Department, Department of Hepatobiliary Surgery, The First Affiliated Hospital of Chongqing Medical University, Chongqing Medical University, Youyi Road 1, Yuzhong, Chongqing 400000, P.R. China

E-mail: huangpchina@sina.com

Key words: MicroRNA, HBx, hepatocarcinogenesis, interaction, mechanism

\section{Introduction}

Liver cancer is one of the most common cancers in the world with an estimated 782,500 new liver cancer cases and 745,500 deaths occurring worldwide during 2012. China accounted for approximately $50 \%$ of the total number of cases and deaths in the world (1). Most (70-90\%) primary live cancers occurring worldwide are hepatocellular carcinoma (HCC) (2). Currently, liver cancer rates are decreasing in some historically high-risk areas, including China and Japan, because of the decreasing HBV infection in China and HCV infection in Japan by elevating hygiene and sanitation (3). Even then, 54\% of HCC cases worldwide are related to HBV (4). Therefore, research on the mechanism of HBV inducing HCC is still a crucial field to reduce the morbidity and find new therapies.

HBV contains four overlapping open reading frames (ORFs), coding the viral envelope (pre-S1/pre-S2/S), core proteins (pre-C/C), viral polymerase and hepatitis $B$ virus $\mathrm{x}$ protein (HBx) (5). HBx, a $\sim 17 \mathrm{kDa}$ protein with 154 amino acids, is an essential factor for HBV replication through accelerating mitochondrial calcium uptake and significantly contributes to $\mathrm{HCC}$ tumorigenesis (6). The properties of $\mathrm{HBx}$ in hepatocarcinogenesis is diversiform, some studies show that HBx can influence proliferation, apoptosis, anti-apoptosis, invasion, motility, mitochondria DNA damage, oxidative stress and epigenetic changes (7). HBx protein is an enigmatic and promiscuous transactivator that can activate a variety of viral and cellular promoters and enhancers (8). Except for protein-protein interaction mediating transcriptional activity, $\mathrm{HBx}$, targeting microRNAs directly or through other bridge protein indirectly, plays its role in $\mathrm{HBV}$-associated HCC development.

MicroRNAs, that have been discovered in humans total more than 2000 species playing important roles in all biological processes by post-transcription regulation of protein-coding genes (9). As regulator, the mature miRNA is incorporated into the RNA-induced silencing complex and promotes target mRNA degradation or repression of translation. Via these mechanism, a number of studies associate miRNAs with numerous functions in tumorigenesis including cell proliferation, differentiation, apoptosis, invasion, metastasis, autophagy (10), epithelial-mesenchymal transition (EMT) (11), lipogenesis (12) and epigenetics (13). Similarly to other cancers, involvement of miRNA in $\mathrm{HCC}$ has been 
demonstrated, aberrant miRNA expression can affect many crucial cancer-associated pathways, including p53, RAS/ MAPK, PI3K/AKT/mTOR, WNT/ $\beta$-catenin and transforming growth factor $\beta$ (TGF- $\beta$ ) (14). Therefore, in view of the importance of HBV infection and dysregulation miRNA in HCC generation, the interaction effects between HBV and miRNA is particularly significant.

Based upon recent studies, the present study aims to review the mechanism and result of the interplay between $\mathrm{HBx}$ and miRNA in HBV-related HCC, which provides help to further clarify the regulation role of $\mathrm{HBx}$ protein for miRNA in tumor development.

\section{The mechanism and result of $H B x$ acting on miRNA}

The mechanism of HBx acting on miRNA. Here, we summarize three mainly mechanism for HBx acting upon miRNAs. First of all, HBx alters the expressions of miRNAs by playing a role in the miRNA production process. miRNAs are transcribed by RNA polymerase II to produce a long primary miRNAs transcripts (pri-miRNAs), and then is cleaved into 70-nt precursor miRNAs (pre-miRNAs) by Drosha which is a member of the RNase III family, the key to it is, Drosha has a cofactor DGCR8, which is decreased by HBx through influencing its promoter activity (15). Some studies have indicated that HBV downregulates the expression of DGCR8 by modulating its promoter activity directly, besides, data indicate that HBV induces the expression of YY1, which directly results in inhibition of DGCR8 promoter activity (16). Notably, downregulation of DGCR8 induced by HBV can result in partial repression of miRNA expression, because of the mirtrons locating in the introns of coding genes and using splicing to bypass Drosha-DGCR8 cleavage, are alternative precursors for miRNAs biogenesis and which essential for the generation of miRNAs (16-18).

Except for the afore-mentioned, studies have shown that the HBx RNA appears to be sufficient to downregulate its targeting microRNAs such as the deregulation of miR-15a/miR-16 (19), the data strongly indicate that the HBx RNA, with or without the coding potential, is able to bind and trigger the decay of the corresponding microRNAs, which is reminiscent of induced downregulation of miR-122 by HBV RNA (20) and enhanced microRNA instability by the herpesvirus non-coding RNA (21).

HBx does not bind DNA directly, its multiregulative functions are mediated by its interactions with host factors, such as activator protein-1 and $-2, \mathrm{NF}-\kappa \mathrm{B}$ and ATF2 (22). For instance, $\mathrm{NF}-\kappa \mathrm{B}$ transcriptional activity was significantly enhanced through interacting with $\mathrm{HBx}$, resulting in the increasing of miR-143 (23) and miR-146a (24). In previous studies, HBx was shown to repress the expression of miR-148a transcription through reduced recruitment of p53 to the miR-148a promoter (25). HBx was found to inhibit the normal function of p53 and p53 inhibited the expression of hepatocyte nuclear factor 4a (HNF4a), a key regulator of miR-122 (26) and miR-548p (27) expression in the liver. Besides, via inhibiting the activity of p53 directly, HBx decreases the expression of miR-216b (28) and miR-122. Notably, one miRNA could be regulated by various host proteins, which are the targets of HBx simultaneously, such as miR-122, which could be repressed by p53 and germline development 2 (Gld2, also called PAPD4) (26). HBx alters host gene expression by constitutively activating cytoplasmic signal transduction pathways, and previous studies have shown that HBx could induce the expression of c-Myc which is the crucial protein in tumorigenesis, hence, c-Myc mediated the HBx-induced repression of miR-15a/16 (29). In addition, it has been indicated that there is a HBx-c-Myc-Lin28B axis existing in let-7 regulation pathways, in turn, let-7 inhibited the expression of c-Myc and Lin28B. This antagonism, maintains a balancing equilibrium between these factors in tumorigenesis (30). Beyond that, HBx has previously been shown to activate activator protein-1 (AP-1), and the upregulation of miR-21 by $\mathrm{HBx}$ is through AP-1. Moreover, AP-1 activity is reported to be negatively regulated by PDCD4, leading to the formation of positive feedback loop between AP-1-miR-21-PDCD4 (31). In fact, HBx alone is considered a poor transformer of human and rodent hepatic cells, usually, the function of HBx regulating the expression of miRNA is achieved by a protein complex. Some researchers concluded that HBx downregulates miR-520b through interacting with Sp1 with survivin (32). Also, regulating the level of DNA methylation on the promoter of miRNA is another essential method for $\mathrm{HBx}$ dysregulating the expression of miRNA. In reality, HBx could induce the expression of DNA methyltransferase (DNMTs) which would increase the level of DNA methylation on the promoter of miR-132 resulting in the decreasing of miR-132 (33). Finally, HBx could upregulate the URG11 which stimulates hepatocellular growth by transcriptionally activating the $\beta$-catenin promoter, resulting in the increasing of miR-148a (34). In general, HBx activates some signal pathways or key protein which could be acting on miRNA specifically to dysregulate the expression of miRNA, and induces hepatocarcinogenesis conclusively.

The results of HBx acting on miRNA. The effect of $\mathrm{HBx}$ acting on miRNA has two aspects, upregulation and downregulation. The detailed results are shown below (Table I).

\section{The effect of the particular HBx form on miRNA}

Full length HBx protein (wild-type HBx, wtHBx) and its $\mathrm{C}$-terminal truncated variants (trHBx proteins or $\mathrm{Ct}-\mathrm{HBx}$ ) are both contributing to the development of HCC. trHBx proteins are detected in HCC and differ significantly with wtHBx in their biological activities (62).

The C-terminal region of wtHBx, which is indispensable for wtHBx stability and contributed to the wtHBx-mediated stimulation of $\mathrm{HBV}$ replication, starts from residues 58 and ends up with 140 (63). Under normal circumstances, wtHBx could stimulate the replication of HBV (63), induce apoptosis (64), inhibit cell growth (64), inhibit cell transformation (64) and exert transactivation function (66), as a contrast, trHBx could not play a part in the above-mentioned processes. Nonetheless, wtHBx and trHBx are expressed in hepatocellular carcinoma cells and enhance the invasiveness and metastasis formation simultaneously $(67,68)$.

Researchers previously identified a natural mutant of the HBx gene with C-terminal-deletion from 382 to 401 bp (termed HBx $\Delta 127)$, which strongly enhanced cell proliferation and migration in HCC relative to wild-type HBx (69). The specific 
Table I. The results of $\mathrm{HBx}$ acting on miRNA.

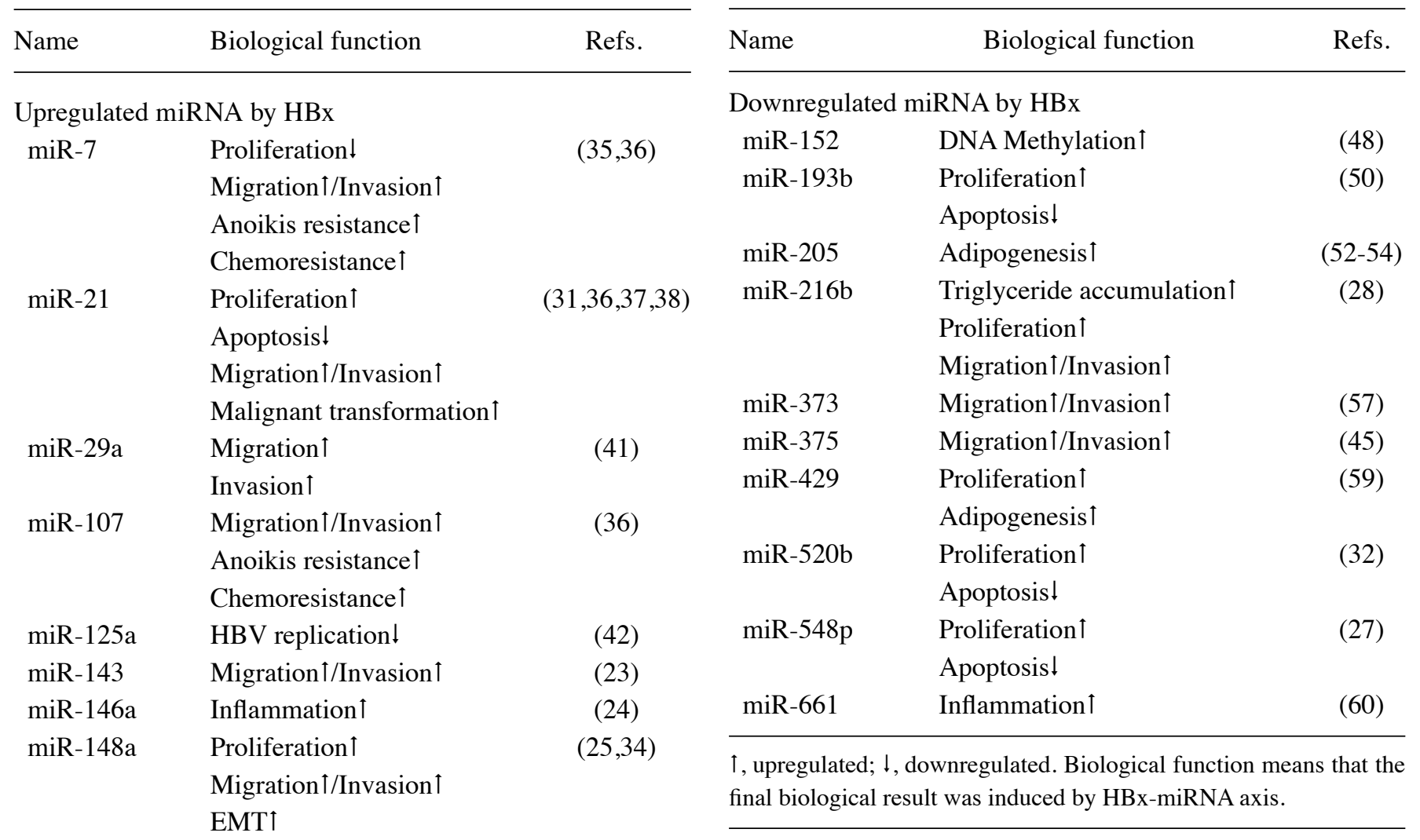

miR-181 Malignant transformation $\uparrow$

miR-215 Proliferation $\uparrow$

miR-221 Proliferation $\uparrow$

miR-224 Migration $\uparrow /$ Invasion $\uparrow$

miR-331-3p Proliferation $\uparrow$

Apoptosis $\downarrow$

miR-374a Proliferation $\uparrow$

Migration $\uparrow /$ Invasion $\uparrow$

miR-545 Proliferation $\uparrow$

Migration $\uparrow /$ Invasion $\uparrow$

miR-602 Proliferation $\uparrow$

Apoptosis $\downarrow$

Downregulated miRNA by HBx

$\begin{array}{ll}\text { Let-7 } & \text { Proliferation } \uparrow \\ & \text { Apoptosis } \downarrow \\ \text { miR-15a } & \text { Cell cycle arrest } \downarrow \\ \text { miR-15b } & \text { HBV replication } \downarrow \\ & \text { Proliferation } \uparrow \\ \text { miR-16 } & \text { PBV replication } \downarrow \\ \text { miR-16-1 } & \text { HBV repliceration } \uparrow \\ \text { miR-101 } & \text { DNA methylation } \uparrow \\ \text { miR-122 } & \text { Proliferation } \uparrow \\ & \text { Adipogenesis } \uparrow \\ & \text { HBV replication } \downarrow \\ \text { miR-132 } & \text { EMT } \uparrow \\ \text { miR-136 } & \text { Proliferation } \uparrow \\ \text { miR-145 } & \text { Apration } \uparrow / \text { Invasion } \uparrow\end{array}$

Table I. Continued

mechanism is that $\mathrm{HBx} \Delta 127$ strongly upregulates miR-215 in hepatoma cells, and the latter directly targets PTPRT (protein tyrosine phosphatase, receptor type T) mRNA which normally acts as a tumor suppressor (49). Another important C-terminaldeletion formation is $\mathrm{HBx} \Delta 35$. It showed that the upregulation of miR-21 which induces hepatocarcinogenesis (70) was mediated by $\mathrm{HBx} \Delta 35$-induced interleukin- 6 pathway followed by activation of STAT3 transcriptional factor (37). Except for the C-terminal-deletion formation of $\mathrm{HBx}$, recent studies suggest that viral-human hybrid RNA transcripts, which play a critical role in promoting $\mathrm{HCC}$ progression, may be the molecules that link HBV infection to HCC development. High-throughput next-generation sequencing studies suggest that HBV DNA integration does not occur at random locations but rather often occurs within or near-repetitive, noncoding sequences, such as long interspersed nuclear elements (LINEs) and short interspersed nuclear elements (SINEs) (71). As a result, there is a possibility that HBV DNA may integrate into host chromosomes at locations that yield particular host/viral fusion products. Researches recently indicated a viral-human hybrid RNA transcript, HBx-LINE ${ }^{1-674}$ (denoted as HBx-LINE1), in HBV-positive HCC (72). HBx-LINE1 contains six miR-122-binding sites, and overexpression of HBx-LINE1 effectively depleted cellular miR-122, promoting hepatic cell epithelial-mesenchymal transition (EMT), proliferation, hepatic injury, $\beta$-catenin signaling activation, E-cadherin reduction and cell migration (44). Besides, HBx-LINE1 acts as a sponge to sequester cellular miR-122 and thus affects the expression and function of miR-122 target genes. miR-122 is a tumor suppressor and a crucial inhibitor factor for HBV infection (73-75). HBx-LINE1 rapidly decreases cellular mature 


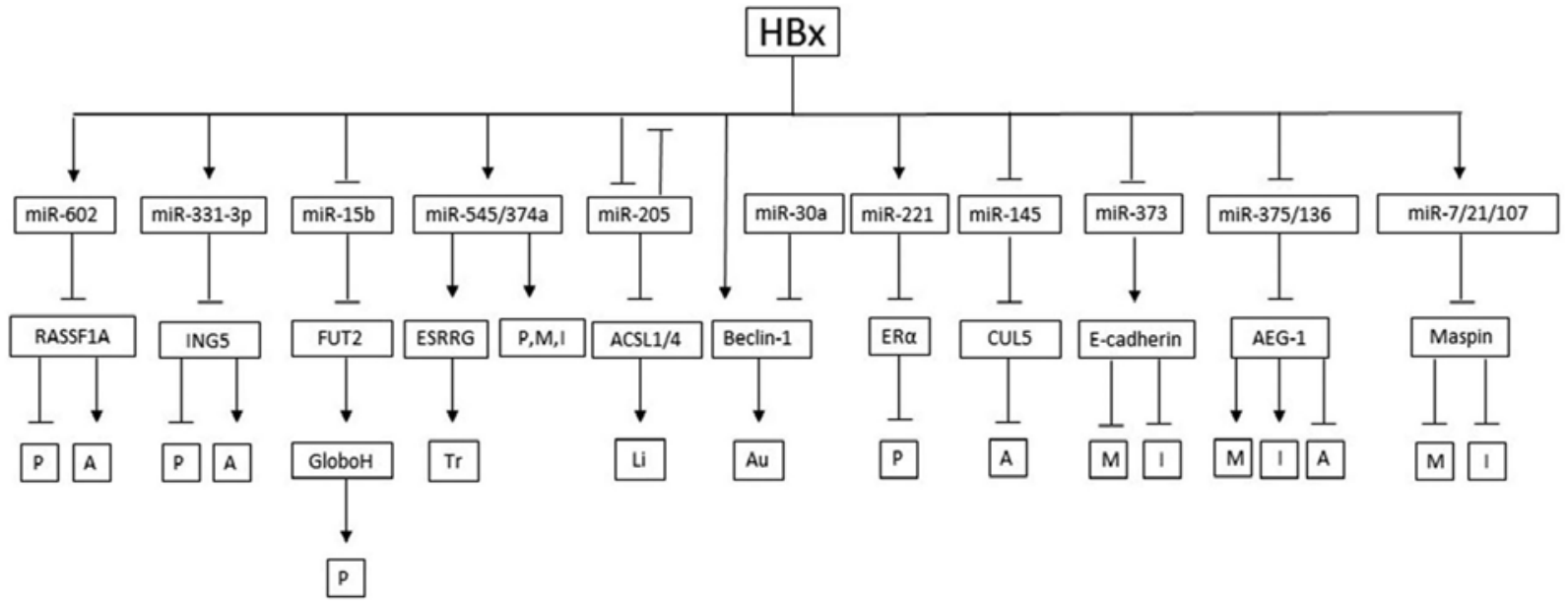

Figure 1. The effect of HBx on microRNAs in hepatocarcinogenesis by unipath methods. $\rightarrow$, promote; - , inhibit; A, apoptosis; P, proliferation; M, migration; I, invasion; Tr, transformation; Au, autophagy; Li, lipogenesis.

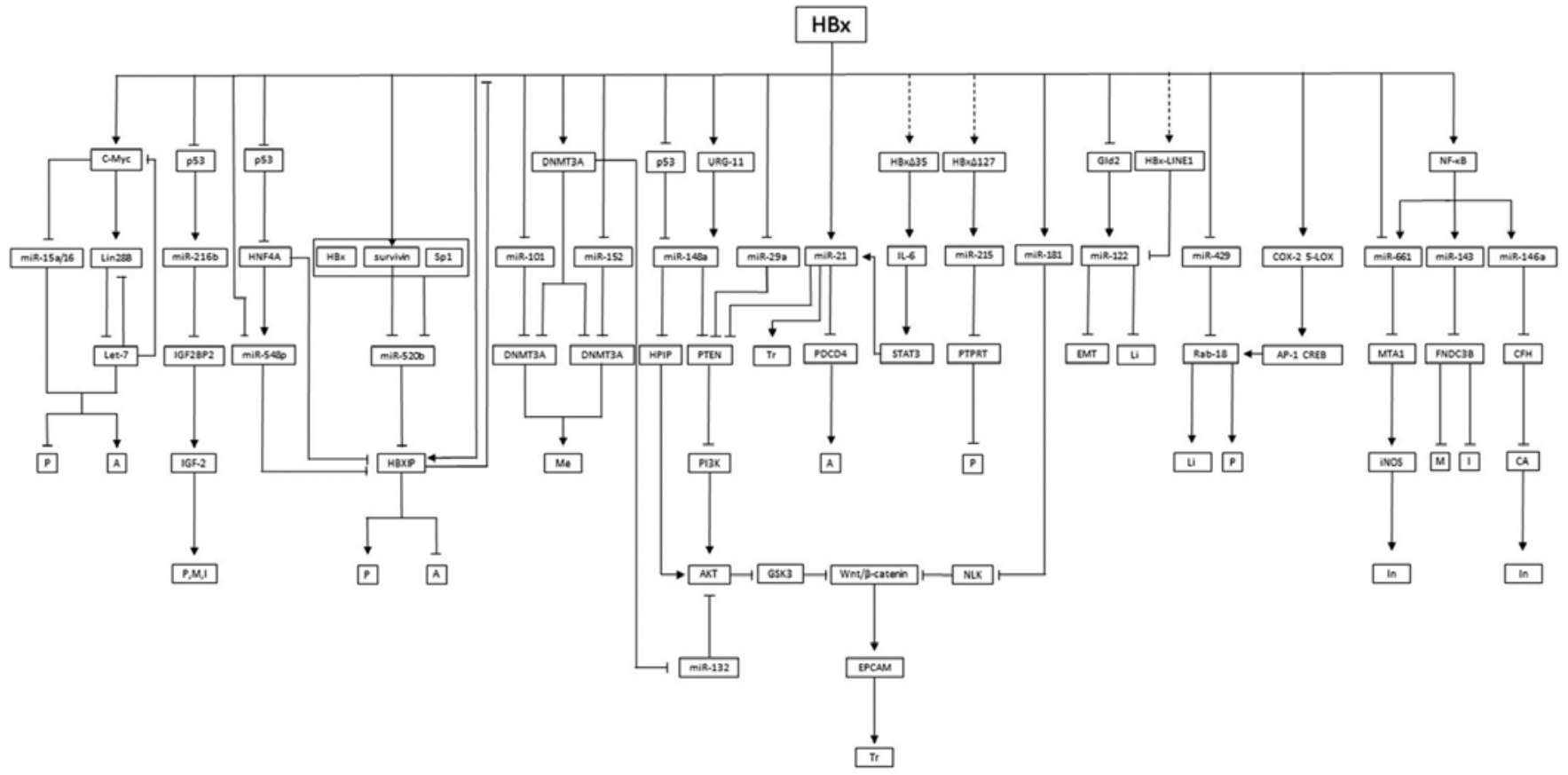

Figure 2. The effect of HBx on microRNAs in hepatocarcinogenesis by complex methods. $\rightarrow$, promote; $\dashv$, inhibit; $\rightarrow$, mutate or fuse; A, apoptosis; P, proliferation; M, migration; I, invasion; Tr, transformation; In, inflammation; Li, lipogenesis; Me, methylation; CA, complement activation; EMT, epithelial mesenchymal transition.

miR-122 level which is an important step for HBV to successfully infect hepatocytes. Interestingly, the same phenomenon was reported in $\mathrm{HCV}$ infection about miR-122 sequestration, in other words, HCV RNA resulted in a miR-122 sequestration directly and induced a global de-repression of target genes by miR-122, ultimately, creating an environment fertile for the long-term oncogenic potential of $\mathrm{HCV}$ (76).

\section{The influence of HBx through regulating miRNA for hepatocarcinogenesis}

HBx regulating the expression of miRNA to alter the characteristic of hepatocyte biological behavior induces a complicated program of hepatocarcinogenesis. In this regulatory network, the concrete mechanism is described in detail below (Figs. 1-3).

Proliferation. The results in previous study suggest that microRNA-602 plays an important regulatory role in HBx-mediated hepatocarcinogenesis by inhibiting the tumor suppressive function of RASSF1A, from very early stage of chronic HBV hepatitis and HBV-positive cirrhosis through HCC (61). A similar mechanism also exists in miR-331-3p which is upregulated by $\mathrm{HBx}$ via enhancing its promoter activity, and miR-331-3p promotes proliferation of HCC cells through targeting ING5 (56). In patients with HCC, 


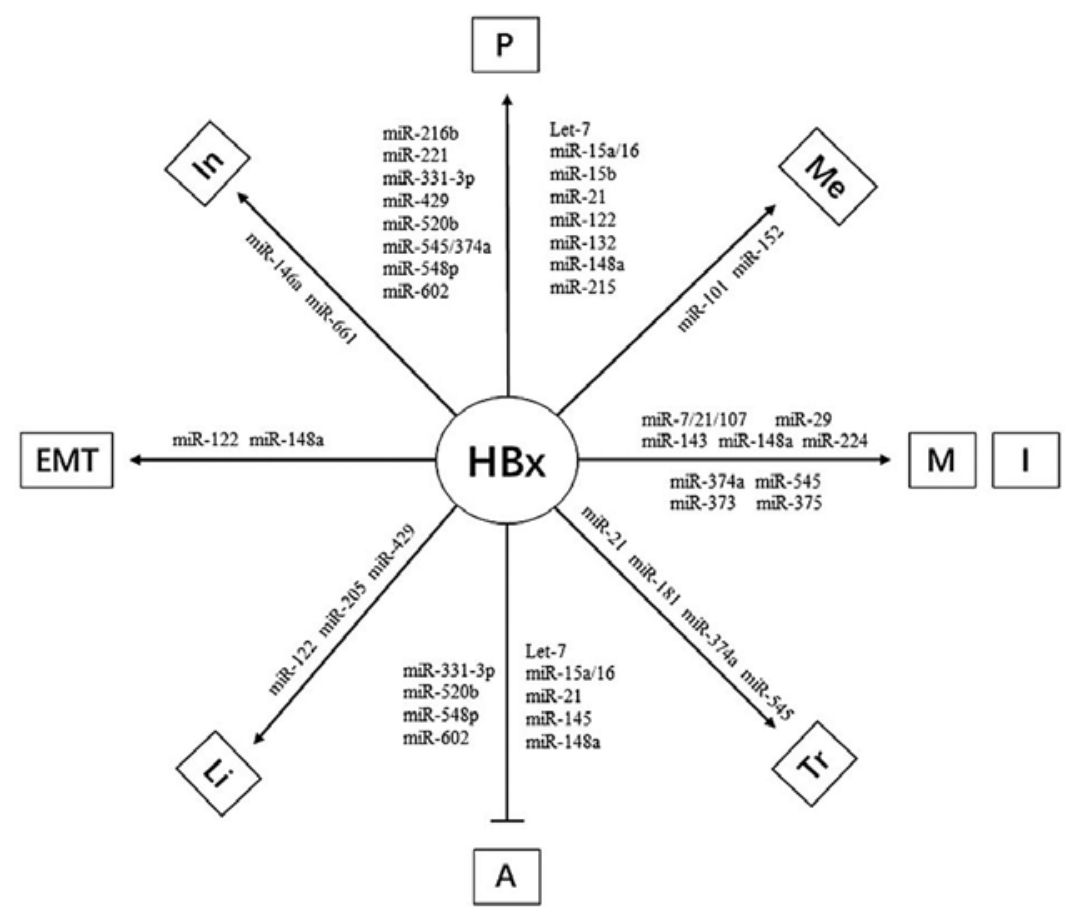

Figure 3. The final result of HBx influencing hepatocarcinogenesis through miRNAs. $\rightarrow$, promote; - , inhibit; A, apoptosis; P, proliferation; M, migration; I, invasion; Tr, transformation; In, inflammation; Li, lipogenesis; Me, methylation; EMT, epithelial mesenchymal transition.

miR-216b, which could be reduced by $\mathrm{HBx}$, functions as a tumor suppressor by targeting IGF2BP2 and subsequently suppressing the downstream IGF2, AKT/mTOR and MAPK/ ERK signaling pathways, finally, inducing the proliferation (28). Several long non-coding RNAs (lncRNAs) also play various roles in HCC progression. The Ftx transcript, which is a conserved functional lncRNA, encodes 4 microRNAs in its introns (77), and intron 12 encodes 1 cluster of 2 microRNAs (miR-374b and miR-421) while intron $b$ encodes 1 related cluster of 2 microRNAs (miR-374a and miR-545). miR-545/374a is positively regulated by $\mathrm{HBx}$, and promotes HCC cell proliferation via downregulating ESRRG (estrogenrelated receptor gamma) (58).

miR-16 family (miR-15a, miR-15b and miR-16) members are frequently suppressed by HBx expression. CCND1 promotes cell cycle progression, and is downregulated by miR-16 directly (29). Moreover, FUT2, which is the primary synthetase of Globo $\mathrm{H}$, is the target of miR-15b (40). Globo $\mathrm{H}$ is a member of the family of antigenic carbohydrates that are highly expressed in various types of cancers as cancerassociated carbohydrate antigens (78) and inducing the proliferation. miR-148a, inhibited by $\mathrm{HBx}$ through decreasing the recruitment of p53 in its promoter region, decreases the expression of PTEN which can repress the activity of PI3K and HPIP (hematopoietic pre-B cell leukemia transcription factor-interacting protein) which regulates cancer cell growth through activation of AKT and ERK $(25,34)$, in addition, miR-132, another target of HBx and downregulated through methylation of its promoter region, represses the expression of Akt directly (33).

In HCC, HBx activates Rab18 through downregulating miR-429 directly, synchronously, HBx activates Rab18 promoter through COX-2 and 5-LOX involving AP-1 and CREB, in brief, there are two pathways such as $\mathrm{HBx} /$ COX-2/5-LOX/AP-1/CREB/Rab18 and HBx/miR-429/Rab18 involved in hepatocarcinogenesis (59). Similar regulatory mechanism presents in regulation of $\mathrm{HBx}$ for miR-520b. Actually, HBx alone is considered a poor transformer in human hepatic cells, some oncogenes, such as H-ras or c-Myc, is necessary for accelerating hepatocarcinogenesis (79). Experimental investigation shows that HBx downregulates miR-520b through interacting with Sp1 with survivin, and mammalian hepatitis B X-interacting protein (HBXIP) which was originally identified as a binding protein of $\mathrm{HBx}$ is the target protein of miR-520b and induces the proliferation, in a word, HBX-Sp1-survivin complex increases the expression of HBXIP by repressing the miR-520b (32). Notably, HBx also directly upregulate HBXIP in hepatoma cells through inducing demethylation of $\mathrm{CpG}$ islands of HBXIP promoter with its partner survivin. Adversely, miR$520 \mathrm{~b}$ targets mitogen activated protein kinase kinase kinase 2 (MEKK2) and cyclin D1 inhibits the proliferation of liver cancer cells (80), indicating the multiple function of $\mathrm{HBx}$ in hepatocarcinogenesis. With regard to HBXIP, it is a new oncoprotein which was originally identified by its interaction with the C-terminus of HBx. The function of HBXIP protein is to negatively regulate $\mathrm{HBx}$ activity and thus to alter the replication life cycle of the virus (81). Besides, miR-548p, which is reduced by hepatocyte nuclear factor-4a (HNF4A) mediated by HBx downregulates HBXIP by directly targeting 3'UTR of HBXIP mRNA and induces the tumorigenesis finally. Interestingly, except for $\mathrm{HBx} / \mathrm{HNF} 4 \mathrm{~A} / \mathrm{miR}-548 \mathrm{p} / \mathrm{HBXIP}$ regulation axes, HBx suppresses the expression of miR-548p directly, furthermore, HNF4A directly downregulates the 
transcription of HBXIP by binding to the first exon, which is not dependent on post-transcriptional regulation pathway by miR-548p (27).

Moreover, the identification of potent mutant of $\mathrm{HBx}$ in hepatocarcinogenesis is significant, such as $\operatorname{HBx} \Delta 127$ and $\mathrm{HBx} \Delta 35$. For regulating miR-21, $\mathrm{HBx}$ and $\mathrm{HBx} \Delta 35$ play a part concurrently. Discriminatively, $\mathrm{HBx}$ protein increases the expression of miR-21 directly, on the contrary, $\mathrm{HBx} \Delta 35$ depends on IL-6 and STAT3 which are the targets of HBx $\Delta 127$ at the same time, and $\mathrm{HBx} \Delta 127$ regulates the STAT3 through inducing the miR-215 and repressing protein tyrosine phosphatase receptor type T (PTPRT) which is a tumor suppressor $(37,48,49)$.

Previous data indicate that estrogen receptor- $\alpha(E R \alpha)$ has protective effects on HCC (82). As a result, miR-221 negatively regulates $\mathrm{ER} \alpha$ expression by interaction with the 3'-untranslated region (3'UTR) of ER $\alpha$ in breast cancer (83). To date, it has been found that upregulation of miR-221 was unregulated by $\mathrm{HBx}$ protein in $\mathrm{HCC}$, and the overexpression of miR-221 was found to induce cell proliferation by suppressing $\mathrm{ER} \alpha(51)$. Estrogens are well accepted as cancer-promoting agents in both the breast and the uterus (84). However, they play a part in contradictory influence to protect individuals against HCC possibly dependent on the estrogens through tissue-specific selective ER modulators (85).

Interestingly, $\mathrm{HBx}$ is not only inducing proliferation. In a previous study, data surprisingly revealed that HBx decreases cell proliferation of HCC cells by suppressing EGFR protein expression, mechanically, targeting EGFR mRNA 3'UTR by upregulated microRNA-7 (miR-7) in response to HBx accounts for the suppression of EGFR protein level in $\mathrm{HBX}$-expressing HCC cells (35). Furthermore, EGFR has also been reported to induce miR-7 transcription relying on its tyrosine kinase activity (86), suggesting miR-7 as a negative feedback regulator of EGFR expression. Thus, the roles of HBx in proliferation through regulating miRNA remain controversial, there is a delicate balance between inducement and inhibition.

Apoptosis. In hepatocarcinogenesis, $\mathrm{HBx}$ regulates apoptosis by increasing or decreasing miRNAs. For example, as mentioned above, HBx regulates miR-21, miR-331-3p, miR-520b, miR-548p and miR-602 via corresponding mechanism to induce the proliferation of hepatocytes, these regulatory networks could repress apoptosis of hepatocyte coinstantaneous. Main reason of this phenomenon is that the target proteins of this miRNA, such as RASSF1A and HBXIP, could not only influence proliferation but also apoptosis. Furthermore, as a member of the Cullin-RING E3 ubiquitin family, Cullin-5 (CUL5) has been reported to be functionally involved in numerous cellular activities including the cell cycle and apoptosis (87). CUL5 is the targets of miR-145 which is downregulated by $\mathrm{HBx}$, finally, the overexpression of CUL5 reduces apoptosis.

Anoikis, from the Greek word 'homelessness', is a particular programmed apoptotic death due to loss or inappropriate cell adhesion (88). In spite of its unique definition, anoikis is essentially an apoptotic process (89). Mammary serine protease inhibitor (Maspin, also named serpin B5) which is a member belonging to the serine protease inhibitor (serpin) superfamily (90) has been shown to reduce tumor growth, metastasis and angiogenesis (91). For hepatocarcinogenesis, taken together, recent study demonstrated that $\mathrm{HBx}$ enhanced the levels of microRNA-7, miR-107 and miR-21 to promote $\mathrm{HCC}$ tumor progression involving anoikis resistance by directly targeting and suppressing maspin expression (36). As a result, the increase of anoikis resistance of HCC cell would lead to acquirement of the ability to survive in circulation, and finally presents distant metastasis. In a word, proliferation, apoptosis, invasion and metastasis supplement each other, and that they could not play a part isolated in tumorigenesis without the others.

For regulating apoptosis of HCC cells, feedback loop exists in HBx, miRNA targeting proteins. Programmed cell death 4 (PDCD4), a novel tumor suppressor gene (TSG), which is expressed ubiquitously in normal tissues with highest levels in liver, was recently reported to be downregulated in HCC (92). A recent study reported for the first time that $\mathrm{HBx}$ downregulates PDCD4 and upregulates miR-21 expression, and the low-expression of PDCD4 induced by miR-21 could suppress apoptosis (31). Interestingly, HBx has previously been shown to activate tumor promoting signals including protein kinase $\mathrm{C}$ (PKC) and activator protein-1 (AP-1) (93) and miR-21 is positively regulated by AP-1 (94). The upregulation of miR-21 by $\mathrm{HBx}$ may be through AP-1. Moreover, AP-1 activity is reported to be negatively regulated by PDCD4 (95), leading to the formation of positive feedback loop between AP-1/miR-21/ PDCD4. Besides, Lin28, which is oncofetal gene, is thought to promote tumorigenesis upon re-expression in somatic cells. Lin28B, as a homologue of Lin28, was first cloned from and shown to be overexpressed in human hepatocellular carcinoma cells and clinical samples (96). Due to the pleiotropic functions of $\mathrm{HBx}$, it demonstrated that $\mathrm{HBx}$ induced the upregulation of c-Myc in HepG2 cells which is capable of trans-activating Lin28B (29). In brief, HBx/c-Myc/Lin28B axis mediated the repression of let-7, and both c-Myc and Lin28B themselves are the targets of let-7, that is to say, c-Myc/Lin28B and let-7 antagonize each other, maintaining a balancing equilibrium between these factors in apoptosis (30).

Actually, the relationship between HBx and apoptosis is controversial. On the one hand, it has been reported that $\mathrm{HBx}$ could inhibit hepatocyte apoptosis by miRNAs and target proteins, and on the other hand, there is a p53-independent pro-apoptotic effect of HBx in vivo and in vitro (97). In short, the regulation of apoptosis for hepatocarcinogenesis by $\mathrm{HBx}$ targeting miRNA is complicated and multidirectional.

Migration and invasion. HBx does not bind DNA directly, its multi-regulative functions are mediated by its interactions with host factors, such as NF- $\kappa \mathrm{B}$ and p53 $(22,98)$. NF- $\kappa \mathrm{B}$ transcriptional activity was significantly enhanced through interacting with HBx in HBV-HCC (99). Research has shown that upregulation of miR-143 expression transcribed by NF- $\mathrm{B}$ in HBV-HCC promotes cancer cell invasion/migration and tumor metastasis by repression of FNDC3B expression (23). Similarly, HBx inhibits miR-148a transcription through reduced recruitment of p53 to the miR-148a promoter, and the latter suppresses the mTOR pathway through inhibition of HPIP/AKT and HPIP/ERK pathways, furthermore, mTOR is a serine/threonine protein kinase that regulates cell proliferation, migration and invasion. Taken together, HBx suppresses p53-mediated activation of miR- 
148a and miR-148a suppresses liver cancer cell migration and invasion in vitro through inhibition of HPIP expression, which targets the mTOR pathway (25). Importantly, miR-148a could repress PTEN directly which is a phosphoinositide phosphatase that originally was identified as a tumor suppressor frequently promoting tumorigenesis. PTEN was indicated to be able to inhibit migration and invasion through regulation of PI3K/ Akt pathway or SRC family kinases (100). Recent studies have indicated that PTEN was also shown to be a direct target of miR148a and miR-29a, both of them could be upregulated by HBx. Thus, HBx induces the invasion and migration by promoting miR-29a and miR-148a expression, and both of them suppress the expression of PTEN $(34,41)$.

The transmembrane glycoprotein E-cadherin provides a physical link between adjacent cells and is crucial for cell polarity and the structural integrity of tissue (101), loss of E-cadherin is associated with acquisition of metastatic capacity. HBx represses the expression of miR-373 which is a positive regulator of E-cadherin expression, finally, decreased E-cadherin mediated by $\mathrm{HBx}$ induces the invasion and migration in HCC (57). Maspin increases cellular adherence to fibronectin via inducing integrin expression, leading to a reduction of invasion (102). HBx induces microRNA-7/103/107 and miR-21 to suppress maspin expression, finally, decreased Maspin promote tumor progression by downregulated cell adhesion and increased cell motility (36). Besides, HBx increases AEG-1 expression by downregulating miR-375 and miR-136, and increased AEG-1 could induce the migration and invasion in HCC (45). In parallel, expression of miR-545/374a which promotes HCC cell migration and invasion, is positively regulated by $\mathrm{HBV}$ infection and can be induced by $\mathrm{HBx}$ expression (58).

Methylation. Growing evidence additionally supports a role of miRNAs as both targets and effectors in aberrant mechanisms of DNA hypermethylation (103). In mammalian cells, the DNA methyltransferase (DNMT) family contains DNMT1, DNMT3A, and DNMT3B which catalyze the addition of a methyl group to the 5'-CpG dinucleotide of the cytosine ring. Our present study indicated that miR-101 is frequently downregulated in an HBx-expressing HCC cell line, and DNMT3A is a direct target of miR-101, finally, HBx is sufficient to upregulate DNMT3A expression (43). In addition, a study showed that HBx can repress miR-152 which can inhibit DNMT1, miR-152 induces a decrease in global DNA hypermethylation and an increase in the methylation level of two tumor suppressor genes, GSTP1 and E-cadherin (48). In a recent study it was found that $\mathrm{HBx}$ was able to suppress miR-205 expression in hepatoma and liver cells through inducing hypermethylation of miR-205 promoter, resulting in the proliferation of hepatoma. Interestingly, miR-205 can directly target HBx mRNA, and repress the expression of HBx. Thereby, HBx and miR-205 presents a negative feedback control in stimulating the tumor growth process (52).

Taken together, HBx, by dysregulating the DNMTs targets miRNAs, and finally changing the methylation level of tumor suppressor genes and influencing hepatocarcinogenesis.

Epithelial-mesenchymal transition (EMT). In recent studies, it has been suggested that epithelial cancer cells may convert to motile mesenchymal ones by undergoing an epithelialmesenchymal transition (EMT) in tumorigenesis, which is characterized by loss of cell adhesion, repression of E-cadherin expression, acquisition of mesenchymal markers (including $\mathrm{N}$-cadherin, vimentin and fibronectin) and increased cell motility and invasiveness (11).

As mentioned above, HBx-LINE1 promotes hepatocellular carcinoma progression via depleting cellular miR-122 and miR-122 serves as a tumor suppressor and negatively regulates cancer cell proliferation, invasion and metastasis. Reduced miR-122 can activate $\beta$-catenin signaling and induce EMT (44). Besides, RhoA, a member of Ras homolog gene family, is a potential functional target of miR-122, suggesting that miR-122 may block EMT through the direct inhibition of cellular RhoA simultaneously (104).

Except for inducing cell growth, invasion and migration, $\mathrm{HBx} / \mathrm{miR}-148 \mathrm{a} / \mathrm{HPIP} / \mathrm{mTOR}$ axis also promotes EMT. Moreover, miR-148a increases expression of the epithelial marker E-cadherin and decreases the E-cadherin repressor Snail as well as N-cadherin and vimentin, which are mesenchymal markers, accompanied by the inhibition of mTOR signaling. In conclusion, HBx suppresses p53-mediated activation of miR-148a and promotes EMT mediated HPIP (25).

Autophagy. Autophagy is a natural catabolic cellular process for damaged organelles, misfolded proteins and pathogen clearing (105). A previous study has shown that HBV survival and its replication needs autophagy (106), and the HBx protein has been demonstrated to be the major molecule involved in inducing autophagy during HBV infection (107).

Autophagosome formation requires beclin-1 to activate PI3 kinase class III into PI3K-phosphate which in turn recruits effectors such as double FYV6 to initiate this process (108). Previously, it has been shown that HBx induces autophagosome formation via upregulation of beclin-1 expression (107). Besides, HBx-induced autophagosome formation is inhibited by miRNA30a overexpression which inhibits both mRNA and protein expression of beclin-1 directly (109). Simultaneously, the study shows that miR-30a has no effect on the expression of HBx. Briefly, miRNA-30a could successfully inhibit HBx-induced autophagosome formation and induce apoptosis in hepatic cells when HBx was co-expressed along with miRNA-30a which could successfully negate the procarcinogenic effects of $\mathrm{HBx}$ and protect the cells against HBV infection.

Inflammation. In the past decade, abundant research showed that chronic hepatitis $\mathrm{B}$ virus (HBV) or hepatitis $\mathrm{C}$ virus infection accounts for $>75 \%$ hepatocellular carcinoma (HCC) cases (110). Furthermore, HBx has also been implicated in inflammatory response in chronic $\mathrm{HBV}$ infection during $\mathrm{HCC}$ development (111). In this process, HBx activates $N F-\kappa B$ signaling (112) and enhances the expression of its downstream inflammatory targets, such as inducible nitric-oxide synthase (iNOS) (113) which is induced in a calcium/calmodulin-independent manner and generates NO in a sustained manner (114). Recent studies suggest that HBx requires MTA1 (metastatic tumor antigen 1) which plays significant roles in both tumor biology and inflammation to stimulate the iNOS. Besides, MTA1 can be suppressed directly by miRNA-661 which is downregulated by HBx. Interestingly, although the levels of miR-661 
transcript were markedly reduced by $\mathrm{HBx}$, there was no effect of HBx upon the miR-661 promoter luciferase activity, probably, $\mathrm{HBx}$ affects the levels of miR-661 by modulating the stability of miR-661. In conclusion, in chronic inflammatory response, HBx upregulates the expression of MTA1 by repressing the level of miR-661 to induce iNOS, resulting in the increasing of NO which has been implicated in the pathogenesis of inflammatory disorders, including hepatitis B virus-associated hepatocellular carcinoma (60).

The infection of HBV for hepatocytes do not account for the cytopathic, instead, repeating immune responses of the host results in continuous cycles of low-level liver cell destruction and regeneration (115). Because of this mechanism, 15-40\% chronic hepatitis B (CHB) carriers develop liver cirrhosis and hepatocellular carcinoma (HCC) (116). Complement factor $\mathrm{H}(\mathrm{CFH})$, an important negative regulator of the alternative pathway of complement activation, were differentially expressed in HBV-expressing and HBV-free hepatocytes. In hepatocytes and hepatic tissue, $\mathrm{HBx}$ downregulates $\mathrm{CFH}$ expression, and lower $\mathrm{CFH}$ levels in hepatocytes to be a direct cause of the liver inflammation (24). The mechanism of $\mathrm{HBx}$ regulating $\mathrm{CFH}$ is dependent on miR-146a which is an innate immunity-related miRNA and induced by $\mathrm{HBx}$ through enhancing its promoter activity. Luciferase reporter assays demonstrated that miR-146a downregulated CFH mRNA expression in hepatocytes via 3'-untranslated-region (UTR) pairing (24). In brief, aforementioned studies demonstrate that the $\mathrm{HBx} / \mathrm{miR}-146 \mathrm{a} / \mathrm{CFH} / \mathrm{complement}$ activation regulation pathway axis might play an important role in the immunopathogenesis of chronic HBV infection.

Malignant transformation. Accumulating evidence has shown that cancer stem cells (CSCs), such as hepatic stem cells (HSC), have a tumor-initiating capacity and play crucial roles in tumor metastasis (117). Epithelial cell adhesion molecule (EpCAM), containing intracellular domain, EpICD, is a marker of HSCs and CSCs (118) and acts as a mitogenic signal transducer via proteolysis and nuclear translocation, which binds to DNA by a complex with the scaffolding protein FHL2, $\beta$-catenin and lymphoid enhancer factor (LEF)-1 and regulates cell proliferation (119).

Recent studies show that EpCAM can be regulated by miR-181 (120). Furthermore, experimental results suggest that miR-181 is an epigenetic target of HBx (47). In general, HBx induced expression of EpCAM by upregulating miR-181 to promote stemness. Chronic HBV infection often extends for decades, but the afore-mentioned stemness readily appear in liver just prior to the appearance of $\mathrm{HCC}$, actually, the $\mathrm{HBx}$ levels of HBV carriers increase with the length of time in the liver, that is to say, the highest levels of $\mathrm{HBx}$ expression is always seen in the cirrhotic liver. In a word, the mechanism of HCC arising most often from cirrhotic livers can be accounted for HBx promoting 'stemness' by EpCAM through miR-181 in pathologic setting which is central to early-stage tumor development.

Except for miR-181, HBx-miR-21 pathway was prevalent in $\mathrm{HCC}$ cells, it was reported that upregulation of miR-21 was mediated by HBx-induced interleukin- 6 pathway followed by activation of STAT3 transcriptional factor, finally, increased miR-21 is able to induce cell transformation $(37,72)$.
Lipid metabolism. A hallmark of cancer cells is a higher rate of metabolism to sustain cell proliferation and metastasis (121). Cancer cells present excessive caloric intake to keep a positive balance of energy and biosynthetic requirements. Therefore, cancer cells get through shifting lipid acquisition from lipid uptake toward de novo lipogenesis to change membrane properties and protects cells from both endogenous and exogenous damage, which is able to maintain tumorigenesis (122). In brief, cancer cells are always endowed with increasing lipogenesis.

Rab guanosine triphosphatases, which are regulators of vesicular transport in both exocytic and endocytic pathways in eukaryotic cells, are members of the Ras oncogene superfamily (123). Rab18, a member of Ras family, has been reported to be involved in lipogenesis of 3T3-L1 adipocytes (124). Recent studies indicated that miR-429 was able to directly target the 3'-untranslated region of Rab18, showing that Rab18 is one of the target genes of miR-429, furthermore, HBx was able to downregulate miR-429 in hepatoma cells, in conclusion, $\mathrm{HBx}$ induces hepatocarcinogenesis through leading to the dysregulation of lipogenesis of hepatoma cells, depending on $\mathrm{HBx} / \mathrm{miR}-429 / \mathrm{Rab} 18$ regulatory axis (59).

The development of liver cancer might be associated with the accumulation of cholesterol in the tissues as well (125). Acyl-CoA synthetase long-chain family member (ACSL) catalyzes the ATP-dependent acylation of fatty acids into long-chain acyl CoAs (LCA-CoAs), which is the first step in lipid metabolism after fatty acid entry into the cell (126). ACSL1 is one of five isoforms, which is important in activating fatty acid destined for triacylglycerol synthesis (127). Simultaneously, ACSL4 is an essential enzyme in the steroid synthesis (128). Previous research has shown that miR-205 is capable of downregulating ACSL1 and ACSL4 via targeting its $3^{\prime} \mathrm{UTR}$ in hepatoma cells, furthermore, $\mathrm{HBx}$ can repress the expression of miR-205, so as a consequence, HBx induces the accumulation of cholesterol and acceleration of lipogenesis via increasing ACSL1 and ACSL4 as well $(53,54)$.

Except for aforementioned miRNA, miR-122 is the other crucial regulation molecule for cholesterol and fatty-acid metabolism (129). Downregulated miR-122 increases the genes involved in cholesterol biosynthesis such as HMG-CoA reductase and lipid synthesis gene such as Agpat1, Mogat1, Agpat3, Agpat9, Ppap2a and Ppap2c, besides, low-expressed miR-122 enhances TG accumulation through increasing Cidec, also known as FSP27, which is a protein that localizes to lipid droplets, negatively regulating lipolysis (129). In fact, HBx could reduce the miR-122 transcription level via binding and sequestering endogenous miR-122 other than affecting its promoter activity, in addition, $\mathrm{HBx}$ reduced the Gld 2 promoter activity which could increase the specific miRNA stabilization by monoadenylation (26). Recently, a study demonstrated that miR-122 could be stabilized by Gld2 (130), as a result, $\mathrm{HBx}$ is a critical protein for lipid metabolism, which regulates miR-122 via downregulating Gld2 (26).

\section{The effect of miRNA on $\mathrm{HBV}$ replication and $H B x$ expression}

Depending on targeting viral transcripts or cellular factors, specific microRNAs can inhibit viral replication, on the other hand, it enhances viral replication by compromising the host 


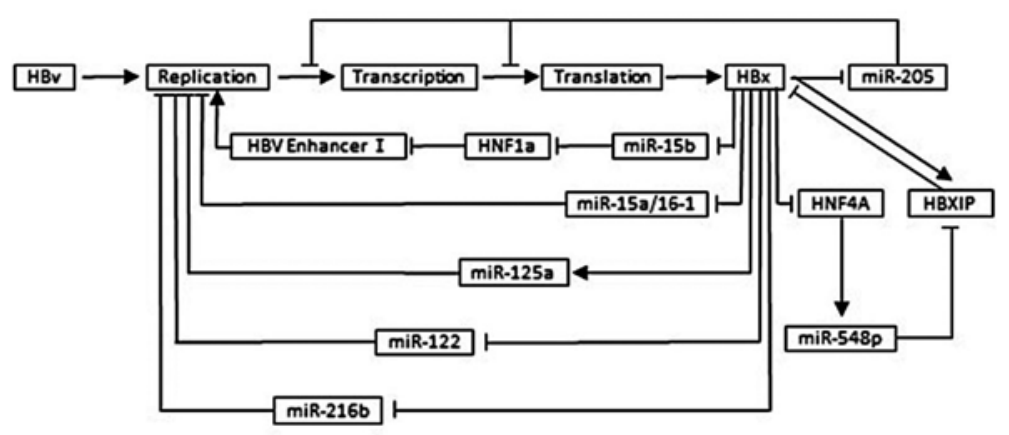

Figure 4. The effect of microRNAs on HBx in hepatocarcinogenesis. $\rightarrow$, promote; $\dashv$, inhibit.

defense system or negative regulators of viral replication as well. For HBV, plenty of miRNAs was suggested to target specific HBV transcripts to inhibit HBV replication being the reason of chronic viral infection, which in turn, alters the expression of specific microRNAs (131). In a word, this regulatory circuit helps HBV to fine-tune its replication, keeping it low to escape the immune system and establish a chronic infection. This mechanism balances the relationship between virus and host to sustain long-term survival of the virus to damage hepatocytes and spread in humans (42) (Fig. 4).

A large amount of evidence has documented that specific microRNAs can target viral transcripts, which was initially thought to serve as an innate immune system against viral infection. It was shown that miR-15a, functions as part of the RISC complex, suppress HBV replication in hepatocytes, simultaneously, miR-15a could efficiently repress HBx expression through its targeting site within the $\mathrm{HBx}$ coding region, interestingly, both the protein and RNA versions of $\mathrm{HBx}$ were able to downregulate miR-15a. In conclusion, miR-15a represses the expression of $\mathrm{HBx}$ by reducing the replication of HBV and targeting the HBx coding region, in turn, HBx clearly induced the repression of miR-15a (19). Importantly, this feedback loop and self-suppression maintain the appropriate level of HBV quantity to induce chronic infection. Except for miR-15a, miR-15b, miR-125a, miR-205 and miR-548p present the same interaction inhibition and self-suppression with HBV replication or HBx expression. miR-15b, another members of miR-15/16 family, directly binds to hepatocyte nuclear factor $1 \alpha(\mathrm{HNF} 1 \alpha)$ mRNA, a negative regulator of HBV enhancer I, to attenuate HNF1 $\alpha$ expression, resulting in transactivation of HBV Enhancer I, causing the enhancement of HBV replication and expression of HBV antigens, including $\mathrm{HBx}$ protein (39). Interestingly, this study indicated that $\mathrm{HBx}$ downregulates the level of intracellular miR-15b at well, also, it has been reported that $\mathrm{HBx}$ protein can stimulate the DNA binding activity of HNF1 $\alpha$ (132). As a consequence, miR-15b and HBx forms a complex interaction network to sustain, to a certain extent, expression of $\mathrm{HBx}$ and virus replication. As for miR-125a, researchers found a self-inhibitory feedback loop in which $\mathrm{HBV}$, through $\mathrm{HBx}$, increases the expression of miR-125a, that in turn interferes with expression of HBV surface antigen, thus repressing viral replication. Besides, the function of miR-205 seems simpler and more efficient in regulating $\mathrm{HBV}$ replication and $\mathrm{HBx}$ expression, because recent study demonstrated that $\mathrm{HBx}$ was able to suppress
miR-205 expression in hepatoma and liver cells, in turn, miR-205 can directly target HBx mRNA and downregulated HBx. More complicated, HBx can repress the expression of miR-548p $(133,134)$, depending on inducing HF4A which is the important regulatory molecule for hepatocyte transformation and hepatocarcinogenesis (27). Furthermore, miR-548p downregulates HBXIP by directly targeting 3'UTR of HBXIP mRNA, and decreased miR-548p through the above mechanism inducing the upregulation of HBXIP which is a new oncoprotein. Interestingly, HBXIP can be upregulated by $\mathrm{HBx}$ directly, furthermore, HBx can repress the expression of miR-548p directly other than getting through HNF4a exclusively, the latter, HNF4a can repress the HBXIP, and HBXIP, downstream element of this regulatory network, can suppress the expression of HBx (27). To sum up, HBx/ HNF4A/miR-548p/HBXIP constitute a complex regulatory circuit to induce tumorigenesis and sustain an appropriate level of HBx and chronic infection state.

Except for self-suppression and interaction suppression between $\mathrm{HBx}$ and miRNA to maintain the appropriate level HBV replication and $\mathrm{HBx}$ expression, miRNA mediated by $\mathrm{HBx}$ also can induce the replication of HBV, meanwhile, increasing the expression of HBx. miR-122 and miR-216b can be repressed by HBx directly and indirectly, further, this miRNA will repress the replication of $\operatorname{HBV}(26,28)$. Hence, downregulation of miR-122 and miR-216b can induce the replication of $\mathrm{HBV}$, and as a result, increasing the expression of HBx, to constitute a positive feedback and promote tumorigenesis. Whether suppression or facilitation of HBV replication and $\mathrm{HBx}$ expression, will eventually promote chronic infection and hepatocarcinogenesis, or are merely methods to adapt for HBV survival in human liver cells, to spread in human and giving rise to more serious liver impairment, which leads ultimately to liver cancer, need further clarification.

\section{Conclusion}

As mentioned above, in the present study we reviewed the recent findings on the interaction between $\mathrm{HBx}$ and miRNA and their significance in hepatocarcinogenesis. An increasing number of research shows that the interaction of $\mathrm{HBx}$ and miRNA regulates numerous biological processes such as proliferation, apoptosis, migration, invasion, methylation, EMT, autophagy, inflammation, transformation and lipogenesis. Moreover, at the same time, miRNA can also regulate 
the expression of $\mathrm{HBx}$, they constitute a feedback in mediating $\mathrm{HBV}$ replication and $\mathrm{HBx}$ expression. Therefore, making it clear that the interaction of $\mathrm{HBx}$ and miRNA will contribute to an overall comprehension of HCC formation. Besides, by means of acting on targets which are referred to in the present review, some novel therapeutic strategies for $\mathrm{HBV}$-associated HCC patients are likely to be discovered.

\section{Acknowledgements}

Dr Dan Song (Department of Hepatobiliary Surgery, The First Affiliated Hospital of Chongqing Medical University, Chongqing Medical University) is gratefully acknowledged for his invaluable cooperation in preparing this review.

\section{References}

1. Torre LA, Bray F, Siegel RL, Ferlay J, Lortet-Tieulent J and Jemal A Global cancer statistics, 2012. CA Cancer J Clin 65: 87-108, 2015.

2. McGlynn KA, Petrick JL and London WT: Global epidemiology of hepatocellular carcinoma: An emphasis on demographic and regional variability. Clin Liver Dis 19: 223-238, 2015.

3. Center MM and Jemal A: International trends in liver cancer incidence rates. Cancer Epidemiol Biomarkers Prev 20: 2362-2368, 2011.

4. Parkin DM: The global health burden of infection-associated cancers in the year 2002. Int J Cancer 118: 3030-3044, 2006.

5. Seeger C and Mason WS: Hepatitis B virus biology. Microbiol Mol Biol Rev 64: 51-68, 2000.

6. Tang H, Oishi N, Kaneko S and Murakami S: Molecular functions and biological roles of hepatitis B virus x protein. Cancer Sci 97: 977-983, 2006.

7. Xu C, Zhou W, Wang Y and Qiao L: Hepatitis B virus-induced hepatocellular carcinoma. Cancer Lett 345: 216-222, 2014.

8. Kremsdorf D, Soussan P, Paterlini-Brechot $\mathrm{P}$ and Brechot C: Hepatitis B virus-related hepatocellular carcinoma: Paradigms for viral-related human carcinogenesis. Oncogene 25: 3823-3833, 2006.

9. Bartel DP: MicroRNAs: Genomics, biogenesis, mechanism, and function. Cell 116: 281-297, 2004.

10. Wu SY, Lan SH and Liu HS: Autophagy and microRNA in hepatitis B virus-related hepatocellular carcinoma. World J Gastroenterol 22: 176-187, 2016.

11. Zhang J and Ma L: MicroRNA control of epithelial-mesenchymal transition and metastasis. Cancer Metastasis Rev 31: 653-662, 2012

12. Gómez de Cedrón M and Ramírez de Molina A: Microtargeting cancer metabolism: Opening new therapeutic windows based on lipid metabolism. J Lipid Res 57: 193-206, 2016.

13. Peschansky VJ and Wahlestedt C: Non-coding RNAs as direct and indirect modulators of epigenetic regulation. Epigenetics 9: 3-12, 2014.

14. Callegari E, Elamin BK, Sabbioni S, Gramantieri L and Negrini M: Role of microRNAs in hepatocellular carcinoma: A clinical perspective. Onco Targets Ther 6: 1167-1178, 2013.

15. Shan X, Ren M, Chen K, Huang A and Tang H: Regulation of the microRNA processor DGCR8 by hepatitis B virus proteins via the transcription factor YY1. Arch Virol 160: 795-803, 2015.

16. Rodriguez A, Griffiths-Jones S, Ashurst JL and Bradley A: Identification of mammalian microRNA host genes and transcription units. Genome Res 14 (10A): 1902-1910, 2004.

17. Ruby JG, Jan CH and Bartel DP: Intronic microRNA precursors that bypass Drosha processing. Nature 448: 83-86, 2007.

18. Okamura K, Hagen JW, Duan H, Tyler DM and Lai EC: The mirtron pathway generates microRNA-class regulatory RNAs in Drosophila. Cell 130: 89-100, 2007.

19. Wang Y, Jiang L, Ji X, Yang B, Zhang Y and Fu XD: Hepatitis B viral RNA directly mediates down-regulation of the tumor suppressor microRNA miR-15a/miR-16-1 in hepatocytes. J Biol Chem 288: 18484-18493, 2013.

20. Li C, Wang Y, Wang S, Wu B, Hao J, Fan H, Ju Y, Ding Y, Chen L, Chu X, et al: Hepatitis B virus mRNA-mediated miR-122 inhibition upregulates PTTG1-binding protein, which promotes hepatocellular carcinoma tumor growth and cell invasion. J Virol 87: 2193-2205, 2013.
21. Cazalla D, Yario T, Steitz JA and Steitz J: Down-regulation of a host microRNA by a Herpesvirus saimiri noncoding RNA. Science 328: 1563-1566, 2010.

22. Feitelson MA and Lee J: Hepatitis B virus integration, fragile sites, and hepatocarcinogenesis. Cancer Lett 252: 157-170, 2007.

23. Zhang X, Liu S, Hu T, Liu S, He Y and Sun S: Up-regulated microRNA-143 transcribed by nuclear factor kappa B enhances hepatocarcinoma metastasis by repressing fibronectin expression. Hepatology 50: 490-499, 2009.

24. Li JF, Dai XP, Zhang W, Sun SH, Zeng Y, Zhao GY, Kou ZH, Guo Y, Yu H, Du LY, et al: Upregulation of microRNA-146a by hepatitis $\mathrm{B}$ virus $\mathrm{X}$ protein contributes to hepatitis development by downregulating complement factor H. MBio 6: e02459-14, 2015.

25. Xu X, Fan Z, Kang L, Han J, Jiang C, Zheng X, Zhu Z, Jiao H, Lin J, Jiang K, et al: Hepatitis B virus X protein represses miRNA-148a to enhance tumorigenesis. J Clin Invest 123: 630-645, 2013.

26. Peng F, Xiao X, Jiang Y, Luo K, Tian Y, Peng M, Zhang M, Xu Y and Gong G: HBx down-regulated Gld2 plays a critical role in HBV-related dysregulation of miR-122. PLoS One 9: e92998, 2014.

27. Hu XM, Yan XH, Hu YW, Huang JL, Cao SW, Ren TY, Tang YT, Lin L, Zheng L and Wang Q: MicroRNA-548p suppresses hepatitis B virus $\mathrm{X}$ protein associated hepatocellular carcinoma by downregulating oncoprotein HBXIP. Hepatol Res 46: 804-815, 2016.

28. Liu FY, Zhou SJ, Deng YL, Zhang ZY, Zhang EL, Wu ZB, Huang ZY and Chen XP: MiR-216b is involved in pathogenesis and progression of hepatocellular carcinoma through HBx-miR216b-IGF2BP2 signaling pathway. Cell Death Dis 6: e1670, 2015.

29. Wu G, Yu F, Xiao Z, Xu K, Xu J, Tang W, Wang J and Song E: Hepatitis $B$ virus $X$ protein downregulates expression of the miR-16 family in malignant hepatocytes in vitro. Br J Cancer 105: 146-153, 2011

30. Wu G, Huang P, Ju X, Li Z and Wang Y: Lin28B over-expression mediates the repression of let-7 by hepatitis $B$ virus $X$ protein in hepatoma cells. Int J Clin Exp Med 8: 15108-15116, 2015.

31. Qiu X, Dong S, Qiao F, Lu S, Song Y, Lao Y, Li Y, Zeng T, $\mathrm{Hu} \mathrm{J}$, Zhang L, et al: HBx-mediated miR-21 upregulation represses tumor-suppressor function of PDCD4 in hepatocellular carcinoma. Oncogene 32: 3296-3305, 2013.

32. Zhang W, Lu Z, Kong G, Gao Y, Wang T, Wang Q, Cai N, Wang H, Liu F, Ye L, et al: Hepatitis B virus X protein accelerates hepatocarcinogenesis with partner survivin through modulating miR-520b and HBXIP. Mol Cancer 13: 128, 2014.

33. Wei X, Tan C, Tang C, Ren G, Xiang T, Qiu Z, Liu R and Wu Z: Epigenetic repression of miR-132 expression by the hepatitis $B$ virus $x$ protein in hepatitis B virus-related hepatocellular carcinoma. Cell Signal 25: 1037-1043, 2013.

34. Yuan K, Lian Z, Sun B, Clayton MM, Ng IO and Feitelson MA: Role of miR-148a in hepatitis B associated hepatocellular carcinoma. PLoS One 7: e35331, 2012.

35. Chen YJ, Chien PH, Chen WS, Chien YF, Hsu YY, Wang LY, Chen JY, Lin CW, Huang TC, Yu YL, et al: Hepatitis B Virusencoded X Protein downregulates EGFR expression via inducing MicroRNA-7 in hepatocellular carcinoma cells. Evid Based Complement Alternat Med 2013: 682380, 2013.

36. Chen WS, Yen CJ, Chen YJ, Chen JY, Wang LY, Chiu SJ, Shih WL, Ho CY, Wei TT, Pan HL, et al: miRNA-7/21/107 contribute to HBx-induced hepatocellular carcinoma progression through suppression of maspin. Oncotarget 6: 25962-25974, 2015.

37. Li CH, Xu F, Chow S, Feng L, Yin D, Ng TB and Chen Y: Hepatitis B virus X protein promotes hepatocellular carcinoma transformation through interleukin- 6 activation of microRNA-21 expression. Eur J Cancer 50: 2560-2569, 2014.

38. Damania P, Sen B, Dar SB, Kumar S, Kumari A, Gupta E, Sarin SK and Venugopal SK: Hepatitis B virus induces cell proliferation via HBx-induced microRNA-21 in hepatocellular carcinoma by targeting programmed cell death protein 4 (PDCD4) and phosphatase and tensin homologue (PTEN). PLoS One 9: e91745, 2014.

39. Dai X, Zhang W, Zhang H, Sun S, Yu H, Guo Y, Kou Z, Zhao G, Du L, Jiang S, et al: Modulation of HBV replication by microRNA-15b through targeting hepatocyte nuclear factor $1 \alpha$. Nucleic Acids Res 42: 6578-6590, 2014.

40. Wu CS, Yen CJ, Chou RH, Chen JN, Huang WC, Wu CY and Yu YL: Downregulation of microRNA-15b by hepatitis B virus $\mathrm{X}$ enhances hepatocellular carcinoma proliferation via fucosyltransferase 2-induced Globo H expression. Int J Cancer 134: 1638-1647, 2014. 
41. Kong G, Zhang J, Zhang S, Shan C, Ye L and Zhang X: Upregulated microRNA-29a by hepatitis B virus $X$ protein enhances hepatoma cell migration by targeting PTEN in cell culture model. PLoS One 6: e19518, 2011.

42. Mosca N, Castiello F, Coppola N, Trotta MC, Sagnelli C, Pisaturo M, Sagnelli E, Russo A and Potenza N: Functional interplay between hepatitis B virus X protein and human miR-125a in HBV infection. Biochem Biophys Res Commun 449: 141-145, 2014.

43. Wei X, Xiang T, Ren G, Tan C, Liu R, Xu X and Wu Z: miR-101 is down-regulated by the hepatitis $\mathrm{B}$ virus $\mathrm{x}$ protein and induces aberrant DNA methylation by targeting DNA methyltransferase 3A. Cell Signal 25: 439-446, 2013.

44. Liang HW, Wang N, Wang Y, Wang F, Fu Z, Yan X, Zhu H, Diao W, Ding Y, Chen X, et al: Hepatitis B virus-human chimeric transcript $\mathrm{HBx}$-LINE1 promotes hepatic injury via sequestering cellular microRNA-122. J Hepatol 64: 278-291, 2016.

45. Zhao J, Wang W, Huang Y, Wu J, Chen M, Cui P, Zhang W and Zhang Y: HBx elevates oncoprotein AEG-1 expression to promote cell migration by downregulating miR-375 and miR-136 in malignant hepatocytes. DNA Cell Biol 33: 715-722, 2014.

46. Gao F, Sun X, Wang L, Tang S and Yan C: Downregulation of MicroRNA-145 caused by hepatitis B virus X protein promotes expression of CUL5 and contributes to pathogenesis of hepatitis B Virus-associated hepatocellular carcinoma. Cell Physiol Biochem 37: 1547-1559, 2015.

47. Arzumanyan A, Friedman T, Ng IO, Clayton MM, Lian Z and Feitelson MA: Does the hepatitis B antigen HBx promote the appearance of liver cancer stem cells? Cancer Res 71: 3701-3708, 2011.

48. Huang J, Wang Y, Guo Y and Sun S: Down-regulated microRNA-152 induces aberrant DNA methylation in hepatitis $B$ virus-related hepatocellular carcinoma by targeting DNA methyltransferase 1. Hepatology 52: 60-70, 2010.

49. Liu F, You X, Chi X, Wang T, Ye L, Niu J and Zhang X: Hepatitis B virus $\mathrm{X}$ protein mutant $\mathrm{HBx} \Delta 127$ promotes proliferation of hepatoma cells through up-regulating miR-215 targeting PTPRT. Biochem Biophys Res Commun 444: 128-134, 2014.

50. Yip WK, Cheng AS, Zhu R, Lung RW, Tsang DP, Lau SS, Chen Y, Sung JG, Lai PB, Ng EK, et al: Carboxyl-terminal truncated HBx regulates a distinct microRNA transcription program in hepatocellular carcinoma development. PLoS One 6: e22888, 2011.

51. Chen JJ, Tang YS, Huang SF, Ai JG, Wang HX and Zhang LP: HBx protein-induced upregulation of microRNA-221 promotes aberrant proliferation in HBV-related hepatocellular carcinoma by targeting estrogen receptor- $\alpha$. Oncol Rep 33: 792-798, 2015.

52. Zhang T, Zhang J, Cui M, Liu F, You X, Du Y, Gao Y, Zhang S, Lu Z, Ye L, et al: Hepatitis B virus X protein inhibits tumor suppressor miR-205 through inducing hypermethylation of miR-205 promoter to enhance carcinogenesis. Neoplasia 15 : 1282-1291, 2013.

53. Cui M, Xiao Z, Sun B, Wang Y, Zheng M, Ye L and Zhang X: Involvement of cholesterol in hepatitis B virus $X$ protein-induced abnormal lipid metabolism of hepatoma cells via up-regulating miR-205-targeted ACSL4. Biochem Biophys Res Commun 445: 651-655, 2014

54. Cui M, Wang Y, Sun B, Xiao Z, Ye L and Zhang X: MiR-205 modulates abnormal lipid metabolism of hepatoma cells via targeting acyl-CoA synthetase long-chain family member 1 (ACSL1) mRNA. Biochem Biophys Res Commun 444: 270-275, 2014.

55. Lan SH, Wu SY, Zuchini R, Lin XZ, Su IJ, Tsai TF, Lin YJ, Wu CT and Liu HS: Autophagy suppresses tumorigenesis of hepatitis B virus-associated hepatocellular carcinoma through degradation of microRNA-224. Hepatology 59: 505-517, 2014.

56. Cao Y, Chen J, Wang D, Peng H, Tan X, Xiong D, Huang A and Tang H: Upregulated in hepatitis B virus-associated hepatocellular carcinoma cells, miR-331-3p promotes proliferation of hepatocellular carcinoma cells by targeting ING5. Oncotarget 6: 38093-38106, 2015.

57. Arzumanyan A, Friedman T, Kotei E, Ng IO, Lian Z and Feitelson MA: Epigenetic repression of E-cadherin expression by hepatitis B virus X antigen in liver cancer. Oncogene 31: 563-572, 2012.

58. Zhao Q, Li T, Qi J, Liu J and Qin C: The miR-545/374a cluster encoded in the Ftx lncRNA is overexpressed in HBV-related hepatocellular carcinoma and promotes tumorigenesis and tumor progression. PLoS One 9: e109782, 2014.

59. You X, Liu F, Zhang T, Li Y, Ye L and Zhang X: Hepatitis B virus $X$ protein upregulates oncogene Rab18 to result in the dysregulation of lipogenesis and proliferation of hepatoma cells. Carcinogenesis 34: 1644-1652, 2013.
60. Bui-Nguyen TM, Pakala SB, Sirigiri DR, Martin E, Murad F, Kumar R, Kumar R and Kumar R: Stimulation of inducible nitric oxide by hepatitis $\mathrm{B}$ virus transactivator protein $\mathrm{HBx}$ requires MTA1 coregulator. J Biol Chem 291: 1198, 2016.

61. Yang L, Ma Z, Wang D, Zhao W, Chen L and Wang G: MicroRNA-602 regulating tumor suppressive gene RASSF1A is overexpressed in hepatitis B virus-infected liver and hepatocellular carcinoma. Cancer Biol Ther 9: 803-808, 2010.

62. Kew MC: Hepatitis B virus x protein in the pathogenesis of hepatitis B virus-induced hepatocellular carcinoma. J Gastroenterol Hepatol 26 (Suppl 1): 144-152, 2011.

63. Lizzano RA, Yang B, Clippinger AJ and Bouchard MJ: The C-terminal region of the hepatitis $\mathrm{B}$ virus $\mathrm{X}$ protein is essential for its stability and function. Virus Res 155: 231-239, 2011.

64. Schuster R, Gerlich WH and Schaefer S: Induction of apoptosis by the transactivating domains of the hepatitis $\mathrm{B}$ virus $\mathrm{X}$ gene leads to suppression of oncogenic transformation of primary rat embryo fibroblasts. Oncogene 19: 1173-1180, 2000.

65. Tu H, Bonura C, Giannini C, Mouly H, Soussan P, Kew M, Paterlini-Bréchot $\mathrm{P}$, Bréchot $\mathrm{C}$ and Kremsdorf D: Biological impact of natural $\mathrm{COOH}$-terminal deletions of hepatitis $\mathrm{B}$ virus $\mathrm{X}$ protein in hepatocellular carcinoma tissues. Cancer Res 61: 7803-7810, 2001

66. Sirma H, Giannini C, Poussin K, Paterlini P, Kremsdorf D and Bréchot C: Hepatitis B virus X mutants, present in hepatocellular carcinoma tissue abrogate both the antiproliferative and transactivation effects of HBx. Oncogene 18: 4848-4859, 1999.

67. Ma NF, Lau SH, Hu L, Xie D, Wu J, Yang J, Wang Y, Wu MC, Fung J, Bai X, et al: $\mathrm{COOH}$-terminal truncated $\mathrm{HBV} \mathrm{X}$ protein plays key role in hepatocarcinogenesis. Clin Cancer Res 14: 5061-5068, 2008

68. Sze KM, Chu GK, Lee JM and Ng IO: C-terminal truncated hepatitis $\mathrm{B}$ virus $\mathrm{x}$ protein is associated with metastasis and enhances invasiveness by C-Jun/matrix metalloproteinase protein 10 activation in hepatocellular carcinoma. Hepatology 57: 131-139, 2013.

69. Zhang H, Shan CL, Li N, Zhang X, Zhang XZ, Xu FQ, Zhang S, Qiu LY, Ye LH and Zhang XD: Identification of a natural mutant of HBV X protein truncated 27 amino acids at the $\mathrm{COOH}$ terminal and its effect on liver cell proliferation. Acta Pharmacol Sin 29: 473-480, 2008.

70. McDaniel K, Herrera L, Zhou T, Francis H, Han Y, Levine P, Lin E, Glaser S, Alpini G and Meng F: The functional role of microRNAs in alcoholic liver injury. J Cell Mol Med 18: 197-207, 2014.

71. Ding D, Lou X, Hua D, Yu W, Li L, Wang J, Gao F, Zhao N, Ren G, Li L, et al: Recurrent targeted genes of hepatitis B virus in the liver cancer genomes identified by a next-generation sequencing-based approach. PLoS Genet 8: e1003065, 2012.

72. Lau CC, Sun T, Ching AK, He M, Li JW, Wong AM, Co NN, Chan AW, Li PS, Lung RW, et al: Viral-human chimeric transcript predisposes risk to liver cancer development and progression. Cancer Cell 25: 335-349, 2014.

73. Lanford RE, Hildebrandt-Eriksen ES, Petri A, Persson R, Lindow M, Munk ME, Kauppinen S and Ørum H: Therapeutic silencing of microRNA-122 in primates with chronic hepatitis C virus infection. Science 327: 198-201, 2010.

74. Shimakami T, Yamane D, Jangra RK, Kempf BJ, Spaniel C, Barton DJ and Lemon SM: Stabilization of hepatitis C virus RNA by an Ago2-miR-122 complex. Proc Natl Acad Sci USA 109: 941-946, 2012.

75. Bandiera S, Pfeffer S, Baumert TF and Zeisel MB: miR-122 - a key factor and therapeutic target in liver disease. J Hepatol 62: 448-457, 2015.

76. Luna JM, Scheel TK, Danino T, Shaw KS, Mele A, Fak JJ, Nishiuchi E, Takacs CN, Catanese MT, de Jong YP, et al: Hepatitis C virus RNA functionally sequesters miR-122. Cell 160: 1099-1110, 2015.

77. Romito A and Rougeulle C: Origin and evolution of the long non-coding genes in the X-inactivation center. Biochimie 93: 1935-1942, 2011

78. Astronomo RD and Burton DR: Carbohydrate vaccines: Developing sweet solutions to sticky situations? Nat Rev Drug Discov 9: 308-324, 2010.

79. Kim YC, Song KS, Yoon G, Nam MJ and Ryu WS: Activated ras oncogene collaborates with $\mathrm{HBx}$ gene of hepatitis $\mathrm{B}$ virus to transform cells by suppressing $\mathrm{HBx}$-mediated apoptosis. Oncogene 20: 16-23, 2001. 
80.Zhang W, Kong G, Zhang J, Wang T, Ye L and Zhang X: MicroRNA-520b inhibits growth of hepatoma cells by targeting MEKK2 and cyclin D1. PLoS One 7: e31450, 2012.

81. Melegari M, Scaglioni PP and Wands JR: Cloning and characterization of a novel hepatitis $\mathrm{B}$ virus $\mathrm{x}$ binding protein that inhibits viral replication. J Virol 72: 1737-1743, 1998

82. Naugler WE, Sakurai T, Kim S, Maeda S, Kim K, Elsharkawy AM and Karin M: Gender disparity in liver cancer due to sex differences in MyD88-dependent IL-6 production. Science 317: 121-124, 2007.

83. Zhao JJ, Lin J, Yang H, Kong W, He L, Ma X, Coppola D and Cheng JQ: MicroRNA-221/222 negatively regulates estrogen receptor alpha and is associated with tamoxifen resistance in breast cancer. J Biol Chem 283: 31079-31086, 2008.

84. Pike MC and Spicer DV: Hormonal contraception and chemoprevention of female cancers. Endocr Relat Cancer 7: 73-83, 2000.

85. Dutertre M and Smith CL: Molecular mechanisms of selective estrogen receptor modulator (SERM) action. J Pharmacol Exp Ther 295: 431-437, 2000.

86. Chou YT, Lin HH, Lien YC, Wang YH, Hong CF, Kao YR, Lin SC, Chang YC, Lin SY, Chen SJ, et al: EGFR promotes lung tumorigenesis by activating miR-7 through a Ras/ERK/ Myc pathway that targets the Ets2 transcriptional repressor ERF. Cancer Res 70: 8822-8831, 2010.

87. Lubbers J, Lewis S, Harper E, Hledin MP, Marquez GA, Johnson AE, Graves DR and Burnatowska-Hledin MA Resveratrol enhances anti-proliferative effect of VACM-1/cul5 in T47D cancer cells. Cell Biol Toxicol 27: 95-105, 2011.

88. Frisch SM and Francis H: Disruption of epithelial cell-matrix interactions induces apoptosis. J Cell Biol 124: 619-626, 1994.

89. Taddei ML, Giannoni E, Fiaschi T and Chiarugi P: Anoikis: An emerging hallmark in health and diseases. J Pathol 226 380-393, 2012.

90.Zou Z, Anisowicz A, Hendrix MJ, Thor A, Neveu M, Sheng S, Rafidi K, Seftor E and Sager R: Maspin, a serpin with tumorsuppressing activity in human mammary epithelial cells. Science 263: 526-529, 1994

91. Bailey CM, Khalkhali-Ellis Z, Seftor EA and Hendrix MJ: Biological functions of maspin. J Cell Physiol 209: 617-624 2006.

92.Zhang H, Ozaki I, Mizuta T, Hamajima H, Yasutake T, Eguchi Y, Ideguchi $\mathrm{H}$, Yamamoto $\mathrm{K}$ and Matsuhashi S: Involvement of programmed cell death 4 in transforming growth factorbeta1-induced apoptosis in human hepatocellular carcinoma. Oncogene 25: 6101-6112, 2006.

93. Tanaka Y, Kanai F, Ichimura T, Tateishi K, Asaoka Y, Guleng B, Jazag A, Ohta M, Imamura J, Ikenoue T, et al: The hepatitis B virus $X$ protein enhances AP-1 activation through interaction with Jab1. Oncogene 25: 633-642, 2006.

94. Talotta F, Cimmino A, Matarazzo MR, Casalino L, De Vita G, D'Esposito M, Di Lauro R and Verde P: An autoregulatory loop mediated by miR-21 and PDCD4 controls the AP-1 activity in RAS transformation. Oncogene 28: 73-84, 2009.

95. Yang HS, Jansen AP, Nair R, Shibahara K, Verma AK, Cmarik JL and Colburn NH: A novel transformation suppressor, Pdcd4, inhibits AP-1 transactivation but not NF-kappaB or ODC transactivation. Oncogene 20: 669-676, 2001.

96. Guo Y, Chen Y, Ito H, Watanabe A, Ge X, Kodama T and Aburatani H: Identification and characterization of lin-28 homolog B (LIN28B) in human hepatocellular carcinoma. Gene 384: 51-61, 2006

97. Terradillos O, Pollicino T, Lecoeur H, Tripodi M, Gougeon ML, Tiollais P and Buendia MA: p53-independent apoptotic effects of the hepatitis B virus HBx protein in vivo and in vitro. Oncogene 17: 2115-2123, 1998.

98. Ng SA and Lee C: Hepatitis B virus X gene and hepatocarcinogenesis. J Gastroenterol 46: 974-990, 2011

99. Kim SY, Kim JC, Kim JK, Kim HJ, Lee HM, Choi MS, Maeng PJ and Ahn JK: Hepatitis B virus X protein enhances NFkappaB activity through cooperating with VBP1. BMB Rep 41: 158-163, 2008

100.Dasari VR, Kaur K, Velpula KK, Gujrati M, Fassett D, Klopfenstein JD, Dinh DH and Rao JS: Upregulation of PTEN in glioma cells by cord blood mesenchymal stem cells inhibits migration via downregulation of the PI3K/Akt pathway. PLoS One 5: e10350,2010.

101. van Roy F and Berx G: The cell-cell adhesion molecule E-cadherin. Cell Mol Life Sci 65: 3756-3788, 2008.
102. Seftor RE, Seftor EA, Sheng S, Pemberton PA, Sager R and Hendrix MJ: maspin suppresses the invasive phenotype of human breast carcinoma. Cancer Res 58: 5681-5685, 1998.

103. Fabbri M, Garzon R, Cimmino A, Liu Z, Zanesi N, Callegari E, Liu S, Alder H, Costinean S, Fernandez-Cymering C, et al: MicroRNA-29 family reverts aberrant methylation in lung cancer by targeting DNA methyltransferases 3A and 3B. Proc Natl Acad Sci USA 104: 15805-15810, 2007.

104. Wang SC, Lin XL, Li J, Zhang TT, Wang HY, Shi JW, Yang S, Zhao WT, Xie RY, Wei F, et al: MicroRNA-122 triggers mesenchymal-epithelial transition and suppresses hepatocellular carcinoma cell motility and invasion by targeting RhoA. PLoS One 9: e101330, 2014

105. He C and Klionsky DJ: Regulation mechanisms and signaling pathways of autophagy. Annu Rev Genet 43: 67-93, 2009.

106. Tian Y, Sir D, Kuo CF, Ann DK and Ou JH: Autophagy required for hepatitis B virus replication in transgenic mice. J Virol 85: 13453-13456, 2011

107. Tang H, Da L, Mao Y, Li Y, Li D, Xu Z, Li F, Wang Y, Tiollais P, $\mathrm{Li}$ T, et al: Hepatitis B virus X protein sensitizes cells to starvation-induced autophagy via up-regulation of beclin 1 expression. Hepatology 49: 60-71, 2009.

108. Bhogal RH, Weston CJ, Curbishley SM, Adams DH and Afford SC: Autophagy: A cyto-protective mechanism which prevents primary human hepatocyte apoptosis during oxidative stress. Autophagy 8: 545-558, 2012.

109. Kumar S, Gupta P, Khanal S, Shahi A, Kumar P, Sarin SK and Venugopal SK: Overexpression of microRNA-30a inhibits hepatitis B virus X protein-induced autophagosome formation in hepatic cells. FEBS J 282: 1152-1163, 2015.

110. Huo TI, Lee SD and Wu JC: Is diabetes a risk factor for hepatocellular carcinoma? Gastroenterology 127: 360-361, author reply 361-362, 2004

111. Hsieh JL, Wu CL, Lee CH and Shiau AL: Hepatitis B virus X protein sensitizes hepatocellular carcinoma cells to cytolysis induced by E1B-deleted adenovirus through the disruption of p53 function. Clin Cancer Res 9: 338-345, 2003.

112. Su F, Theodosis CN and Schneider RJ: Role of NF-kappaB and myc proteins in apoptosis induced by hepatitis B virus $\mathrm{HBx}$ protein. J Virol 75: 215-225, 2001

113. Majano P, Lara-Pezzi E, López-Cabrera M, Apolinario A, Moreno-Otero R and García-Monzón C: Hepatitis B virus X protein transactivates inducible nitric oxide synthase gene promoter through the proximal nuclear factor kappaB-binding site: Evidence that cytoplasmic location of X protein is essential for gene transactivation. Hepatology 34: 1218-1224, 2001.

114. Jahani-Asl A and Bonni A: iNOS: A potential therapeutic target for malignant glioma. Curr Mol Med 13: 1241-1249, 2013.

115. Chisari FV, Isogawa $\mathrm{M}$ and Wieland SF: Pathogenesis of hepatitis B virus infection. Pathol Biol (Paris) 58: 258-266, 2010.

116. Fattovich G, Stroffolini T, Zagni I and Donato F: Hepatocellular carcinoma in cirrhosis: Incidence and risk factors. Gastroenterology 127 (Suppl 1): S35-S50, 2004.

117. Huang R and Rofstad EK: Cancer stem cells (CSCs), cervical CSCs and targeted therapies. Oncotarget 8: 35351-35367, 2017.

118. Schmelzer E, Wauthier E and Reid LM: The phenotypes of pluripotent human hepatic progenitors. Stem Cells 24: 1852-1858, 2006.

119. Munz M, Baeuerle PA and Gires O: The emerging role of EpCAM in cancer and stem cell signaling. Cancer Res 69: 5627-5629, 2009.

120.Ji J, Zheng X, Forgues M, Yamashita T, Wauthier EL, Reid LM, Wen X, Song Y, Wei JS, Khan J, et al: Identification of microRNAs specific for epithelial cell adhesion moleculepositive tumor cells in hepatocellular carcinoma. Hepatology 62: 829-840, 2015.

121. Zhang F and Du G: Dysregulated lipid metabolism in cancer. World J Biol Chem 3: 167-174, 2012.

122. Rysman E, Brusselmans K, Scheys K, Timmermans L, Derua R, Munck S, Van Veldhoven PP, Waltregny D, Daniëls VW, Machiels J, et al: De novo lipogenesis protects cancer cells from free radicals and chemotherapeutics by promoting membrane lipid saturation. Cancer Res 70: 8117-8126, 2010.

123. Chia WJ and Tang BL: Emerging roles for Rab family GTPases in human cancer. Biochim Biophys Acta 1795: 110-116, 2009.

124. Pulido MR, Diaz-Ruiz A, Jiménez-Gómez Y, Garcia-Navarro S, Gracia-Navarro F, Tinahones F, López-Miranda J, Frühbeck G, Vázquez-Martínez R and Malagón MM: Rab18 dynamics in adipocytes in relation to lipogenesis, lipolysis and obesity. PLoS One 6: e22931, 2011 
125. Morales A, Mari M, Garcia-Ruiz C, Colell A and FernandezCheca JC: Hepatocarcinogenesis and ceramide/cholesterol metabolism. Anticancer Agents Med Chem 12: 364-375, 2012.

126. Parkes HA, Preston E, Wilks D, Ballesteros M, Carpenter L, Wood L, Kraegen EW,Furler SM and Cooney GJ: Overexpression of acyl-CoA synthetase-1 increases lipid deposition in hepatic (HepG2) cells and rodent liver in vivo. Am J Physiol Endocrinol Metab 291: E737-E744, 2006.

127. Li LO, Ellis JM, Paich HA, Wang S, Gong N, Altshuller G, Thresher RJ, Koves TR, Watkins SM, Muoio DM, et al: Liverspecific loss of long chain acyl-CoA synthetase-1 decreases triacylglycerol synthesis and beta-oxidation and alters phospholipid fatty acid composition. J Biol Chem 284: 27816-27826, 2009.

128. Duarte A, Poderoso C, Cooke M, Soria G, Cornejo Maciel F Gottifredi V and Podestá EJ: Mitochondrial fusion is essential for steroid biosynthesis. PLoS One 7: e45829, 2012.
129. Wen J and Friedman JR: miR-122 regulates hepatic lipid metabolism and tumor suppression. J Clin Invest 122: 2773-2776, 2012.

130. D'Ambrogio A, Gu W, Udagawa T, Mello CC and Richter JD Specific miRNA stabilization by Gld2-catalyzed monoadenylation. Cell Rep 2: 1537-1545, 2012.

131. Liu WH, Yeh SH and Chen PJ: Role of microRNAs in hepatitis $\mathrm{B}$ virus replication and pathogenesis. Biochim Biophys Acta 1809: 678-685, 2011

132. Li J, Xu Z, Zheng Y, Johnson DL and Ou JH: Regulation of hepatocyte nuclear factor 1 activity by wild-type and mutant hepatitis B virus X proteins. J Virol 76: 5875-5881, 2002.

133. Piriyapongsa $\mathbf{J}$ and Jordan IK: A family of human microRNA genes from miniature inverted-repeat transposable elements. PLoS One 2: e203, 2007.

134. Yuan Z, Sun X, Liu H and Xie J: MicroRNA genes derived from repetitive elements and expanded by segmental duplication events in mammalian genomes. PLoS One 6: e17666, 2011. 